\title{
O lugar da cotidianidade no planejamento urbano: um olhar a partir do Guarituba (Piraquara/PR)
}

\author{
The place of everyday life in urban planning: \\ an investigation of Guaratuba (Piraquara, State of Paraná)
}

Liria Yuri Nagamine [I]

\begin{abstract}
Resumo
Este artigo apresenta o tema do cotidiano, tendo como objetivo investigar de que forma ele se configura como dimensão importante e fundamental para o planejamento urbano. Escolheu-se, para a análise, o bairro Guarituba, situado no município de Piraquara, periferia da metrópole de Curitiba. 0 procedimento adotado tem como referência a pesquisa participante, com foco para a análise "de perto" e "de dentro" em relação à dimensão "de longe" e "de fora", e a aplicação de entrevistas semiestruturadas a moradores locais. Os resultados apresentam-se pela constituição da historicidade e da produção do espaço para moradia apresentadas a partir da investigação do Guarituba como um todo e de dois lugares dentro dele: 0 Conjunto habitacional Madre Teresa de Calcutá e o Jardim Orquídeas.
\end{abstract}

Palavras-chave: cotidianidade; vida cotidiana; planejamento urbano; lugar; moradia

\begin{abstract}
The article approaches the theme of everyday life, aiming to investigate in what way it constitutes an important and fundamental dimension for urban planning. The neighborhood chosen for analysis was Guarituba, located in the municipality of Piraquara, on the periphery of the Curitiba metropolis. The adopted procedure has participant research as reference, focusing on the analysis performed "closely" and "from within" as opposed to the "far" and "from the outside" dimension. This was accomplished through field observations and semi-structured interviews with local residents. The results address historicity and the production of housing space, based on the investigation of Guarituba as a whole and of two areas within it: the Madre Teresa de Calcutá housing complex and the Jardim Orquídeas allotment.
\end{abstract}

Keywords: everyday life; daily life; urban planning; place; housing. 


\section{Introdução}

Situar o lugar da cotidianidade no planejamento urbano é o principal objetivo desta pesquisa, realizada no bairro do Guarituba, localizado no município de Piraquara, região leste da metrópole de Curitiba (Figura 1). A investigação teve como pressuposto a afirmação de que existe uma relação dialética entre a cotidianidade e o planejamento urbano que precisa ser assimilada na prática, entre gestores, urbanistas e acadêmicos. Argumenta-se que, por esse caminho, os problemas e as contradições da sociedade seriam apreendidos e avaliados, tendo como resultado propostas efetivas em políticas públicas de atuação do Estado. A questão principal consistiu em indagar, dessa forma, se a cotidianidade é uma dimensão, campo ou escala válida, relevante para o planejamento urbano.

Tal pergunta se encontra circunscrita dentro da discussão e da crítica sobre o planejamento urbano realizadas atualmente no Brasil, que apontam para o papel contraditório desempenhado pelo planejamento, por meio do Estado, na produção desigual do espaço das cidades. Contraditório porque o Estado, enquanto ente planejador, é, ao mesmo tempo, um instrumento para a reprodução capitalista e uma possibilidade para a realização de melhorias apropriadas pelo conjunto da sociedade.

Limonad e Castro $(2014)^{1}$ ressaltam, nesse contexto, o desafio do planejamento de atuar em diversas escalas, tratando-se, de acordo com Carlos (2014, p. 25), "de considerar a tendência à mundialização em escalas justapostas, ao mesmo tempo localizando o planejamento no plano da vida e do lugar articulado e redefinido em resposta à reprodução ampliada do capital na escala mundial".

Para a autora, o lugar permite revelar, "no nível do cotidiano, os conflitos do mundo moderno" (Carlos, 2007, p. 20), constituindo-se em um desafio à análise da dinâmica da sociedade contemporânea. À luz do conceito de lugar, portanto, esta pesquisa procurou contribuir com o aprofundamento de visões e perspectivas para o planejamento urbano a partir da cotidianidade.

O Guarituba foi escolhido, por despontar-se como um lugar representativo de grandes desafios urbanos atuais. Ocupado por uma população de aproximadamente 36.527 habitantes ${ }^{2}$ (IBGE, 2016), é um lugar historicamente marcado pela pobreza, precarização do espaço e espoliação urbana, onde as contradições vistas a partir da realidade de desigualdade socioespacial são nítidas na contemporaneidade.

\section{Dos conceitos sobre o cotidiano aos procedimentos de análise}

Nesse sentido, partindo-se da hipótese de que as ações de planejamento urbano interferem no cotidiano da sociedade e vice-versa, sem que técnicos e urbanistas considerem a sua relevância para planejarem a partir dele, o cotidiano foi objeto principal de análise desta investigação.

A cotidianidade, por definição, caracteriza-se pelo que se faz e sucede todos os dias, pelo que se pratica habitualmente e que se 
Figura 1 - Localização do Guarituba na Região Metropolitana de Curitiba

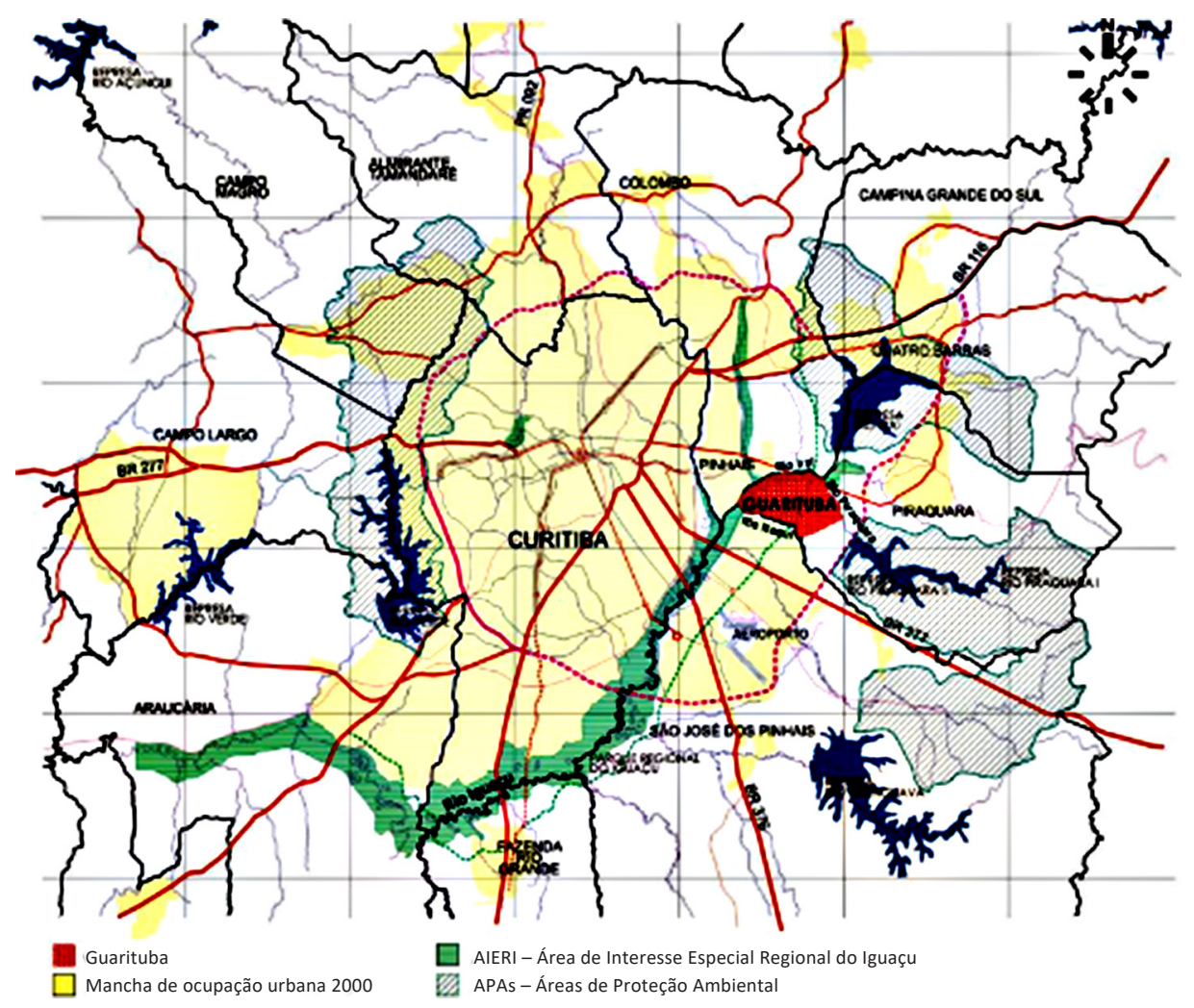

Fonte: adaptado de Comec (1999).

torna a rotina diária de todo homem; enfim, o repetitivo. É por isso que falamos em vida cotidiana, porque essa repetição diária se faz em torno da vida do homem. De acordo com Heller (2014, p. 31), essa vida cotidiana,

Todos a vivem, sem nenhuma exceção, qualquer que seja seu posto na divisão do trabalho intelectual e físico. Ninguém consegue identificar-se com sua atividade humano-genérica a ponto de poder desligar-se inteiramente da cotidianidade. E, ao contrário, não há nenhum homem, por mais "insubstancial" que seja, que viva tão somente na cotidianidade, embora esta o absorva preponderantemente.

Para Heller (ibid., pp. 31-32), a vida cotidiana é também "a vida do homem inteiro", e, sendo assim, ele participa dela "com todos os aspectos de sua individualidade e 
personalidade", mas não possui tempo nem possibilidade de fruir inteiramente todas as capacidades que possui. Além disso, a vida cotidiana é heterogênea, principalmente no que se refere ao conteúdo, significado e importância das atividades que se apresentam de forma hierárquica como condição para se efetivar.

llumina-se de importância, como referência conceitual na investigação realizada, o entendimento que nos traz Lefebvre sobre a cotidianidade. Destaca-se que a principal diferença existente entre os conceitos lefebvrianos sobre o cotidiano em relação ao de outros autores reside na temporalidade. Deve-se, assim, considerar que, enquanto para Heller, os conceitos sobre o cotidiano dizem respeito a todo homem e se inserem também em qualquer tempo; para o filósofo francês, a temporalidade é determinada, pois ele localiza seu conceito de cotidianidade na relação com a modernidade. ${ }^{3}$

Investigando a sociedade europeia das décadas de 1950 e 1960, Lefebvre (1968, pp. 38-39) concluiu que a cotidianidade e a modernidade são duas faces simultâneas da realidade existente na sociedade. 0 cotidiano "é o modesto e o sólido, o que vale por si, aquilo em que as partes e fragmentos se encadeiam num emprego do tempo", e assim somente aparentemente insignificante. Ao mesmo tempo, o moderno é o apenas aparentemente audacioso, "sinal do novo ou da novidade: o sumptuoso, o paradoxal, marcado pela tecnicidade ou pela mundianidade". No entanto, cada um desses aspectos - o cotidiano e o moderno - complementam, mascaram, marcam, legitimam e compensam um ao outro.

Para Lefebvre (ibid., p. 104), o cotidiano visto junto ao moderno não é, dessa forma, um "espaço-tempo abandonado, não é já o campo deixado à liberdade e à razão ou ao desembaraço individuais". Ele é "objeto de todas as preocupações: domínio da organização, espaço-tempo da auto-regulação [sic] voluntária e planificada". Lefebvre (ibid.) propôs a definição de "sociedade burocrática de consumo dirigido", acentuando nela "o caráter racional dessa sociedade, os limites dessa racionalidade (burocrática), o objeto que ela organiza (o consumo em vez da produção) e o plano em que incide o esforço para nele se apoiar: o quotidiano" (ibid., p. 84). Por fim, ele situa o momento em que isso ocorre: no mundo moderno, no qual o espaço da cotidianidade deixa de ser "sujeito" para se tornar objeto da organização social. Assim, em Lefebvre, a "quotidianidade seria o principal produto da sociedade dita organizada, ou de consumo dirigida, assim como seu cenário: a Modernidade" (ibid., p. 104).

0 ponto chave para se compreender a cotidianidade lefebvriana se encontra, desse modo, no aspecto programável da cotidianidade que é percebido na relação com uma modernidade cada vez mais global, sendo este aspecto, o da mundialização, um objetivo estratégico de atuação para o consumo do capital industrial.

A dialética lefebvriana pode aqui ser observada mediante três dimensões: cotidianidade, modernidade e mundialidade. Considerando essas dimensões, o Estado, ao atuar de acordo com a lógica capitalista de produção do espaço, tratou de organizar o espaço habitado pela sociedade, mediante o planejamento urbano. Planejou e priorizou, por exemplo, o uso do carro nas cidades, e as casas foram dimensionadas e projetadas segundo conteúdos de consumo dos novos produtos e facilidades domésticas. 
Na modernidade, os processos políticos, sociais e econômicos atuam em um espaço cada vez mais homogêneo, simultâneo, integrado e global. A isto, seguiram-se formas cada vez mais fragmentadas e especializadas de divisão do trabalho. Esta é uma das razões pelas quais Lefebvre (ibid., pp. 43-44) afirma que:

A quotidianidade não é somente um conceito, mas podemos encarar esse conceito como fio condutor para conhecer a "sociedade" situando o quotidiano no global: o Estado, a técnica e o tecnicismo, a cultura (ou a decomposição da cultura), etc. Tal é a nosso ver a melhor maneira de abordar a questão, a tentativa mais racional para compreender a nossa sociedade e a definir penetrando nela. Não é mais racional proceder assim do que fazer longos rodeios para mal a interpretar?

Sendo a cotidianidade encarada como um conceito para conhecer a sociedade, é importante observar que Lefebvre a distingue da definição de vida cotidiana. Para ele, a cotidianidade resultante do planejamento e da programação da vida cotidiana pelo capitalismo moderno abriga a redução dessa vida cotidiana. Pois, de acordo com o autor, a vida cotidiana diferencia-se do conceito de cotidianidade na medida em que representa a possibilidade: é a atitude social, com a produção pelo ser humano da sua própria vida.

Tendo em vista os conceitos acima relacionados, cabe explicitar alguns aspectos sobre os procedimentos adotados para a análise do objeto de investigação que é o Guarituba. Ressalta-se, primeiramente, que a investigação desse fragmento espacial foi realizada, de acordo com Magnani (2002), "de perto" e "de dentro", mas sem perder de vista a totalidade. Ou seja, os procedimentos utilizados tiveram como objetivo identificar padrões e regularidades a partir da dinâmica do cotidiano, não como um sistema acabado em si; mas que, na interação com outros fragmentos e dimensões de análise, pudessem explicar e apontar caminhos.

Resgatou-se, ainda, a contribuição da antropologia que, através da etnografia urbana, estabeleceu uma estratégia com dois polos de relação: "de um lado, sobre os atores sociais, o grupo e a prática que estão sendo estudados e, de outro, a paisagem em que essa prática se desenvolve, entendida não como mero cenário, mas parte constitutiva do recorte de análise" (Magnani, 2002, p. 18). A pesquisa buscou, à luz dessa estratégia, analisar o modo de produção e reprodução do espaço através do processo de apropriação da casa e de áreas para a moradia no Guarituba no cotidiano, tendo em vista quatro recortes espaciais de referência (Figura 2): (1) ruas Betonex, Herbert Trapp e Juri Danilenko - três vias estruturantes nas quais se concentram o comércio e serviços públicos e privados no Guarituba; (2) rua Pastor Adolfo Weidmann - via mais antiga do Guarituba; (3) Conjunto habitacional Madre Teresa de Calcutá (CHMTC) - construído como uma das ações do PAC/2007, através do Plano de Recuperação Ambiental e Urbanização do Guarituba (Prau/Guarituba), com o propósito de remanejar/reassentar famílias de áreas de situação de risco social e ambiental do lugar; e (4) jardim Orquídeas - constituído por um conjunto de loteamentos igualmente inseridos no Prau/Guarituba, ${ }^{4}$ mas na linha de ação da regularização fundiária e implantação de infraestrutura básica (drenagem, saneamento, estrutura viária). 


\section{Figura 2 - Recortes espaciais de referência para a análise}

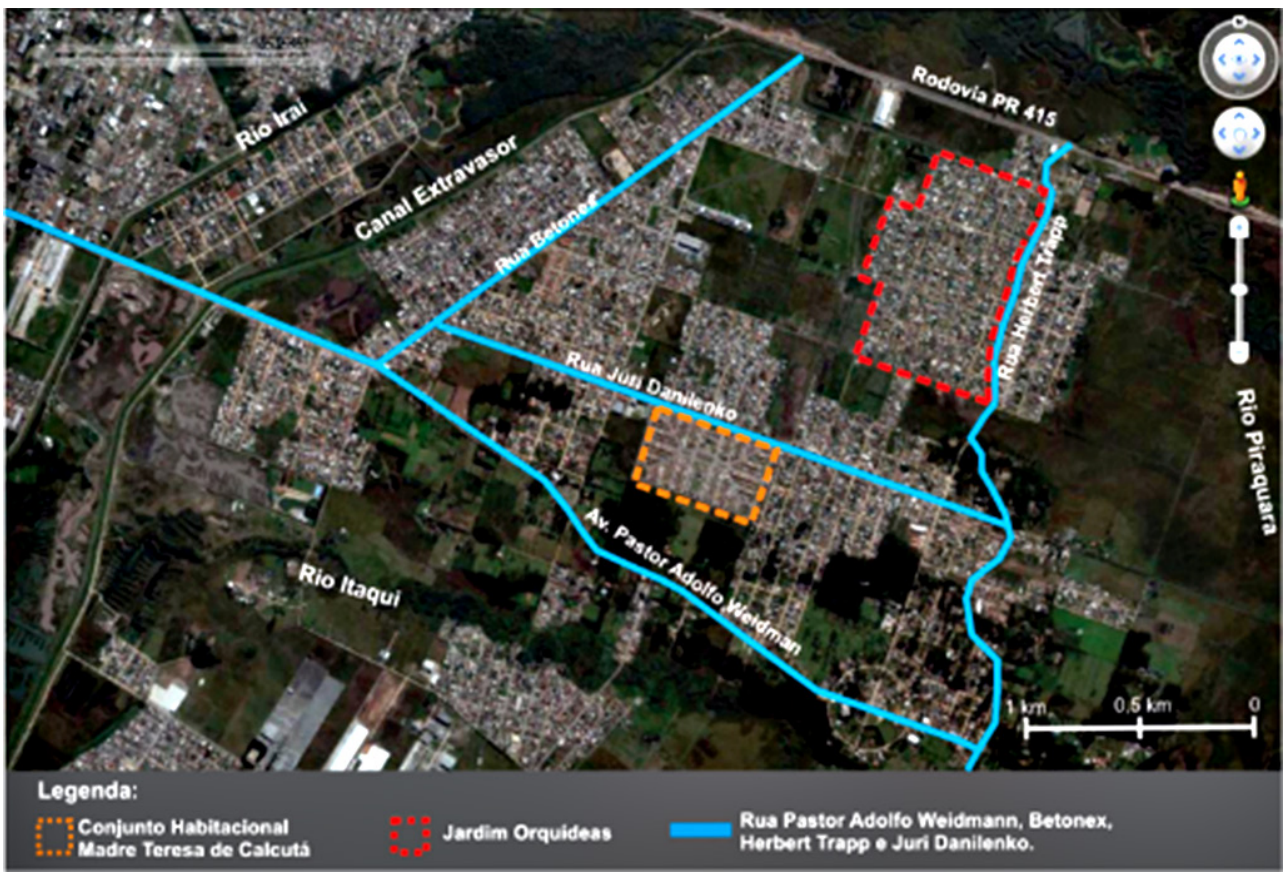

Foto: autora, em 2017.

Nota: base imagem Google Earth (2015).

Tendo como referência esses recortes espaciais e também os princípios da pesquisa participante, quatro procedimentos foram aplicados na investigação da produção do espaço através da cotidianidade e da vida cotidiana dos moradores do Guarituba: (1) trabalho de observação em campo, como forma de aproximação do objeto de pesquisa; (2) entrevistas com interlocutores institucionais que colaboraram com informações adicionais, principalmente a respeito do espaço concebido no Guarituba; (3) trabalho de campo com moradores locais; (4) realização de entrevistas semiestruturadas com 39 moradores locais (16 no CHMTC, 15 no jardim Orquídeas,
5 moradores antigos e 3 comerciantes da rua Betonex), programadas previamente e realizadas entre 6 de outubro e 8 de novembro de 2016.

Finalmente, destaca-se que as entrevistas semiestruturadas foram realizadas tendo em vista perguntas dirigidas que abarcavam os seguintes assuntos:

a) historicidade: investigar a origem dos moradores entrevistados e o percurso até chegarem ao Guarituba, além das razões que os levaram a escolher esse lugar. Investigou-se como era a vida no Guarituba quando chegaram e as principais mudanças que perceberam ao longo do tempo; 
b) produção e apropriação do espaço para moradia: investigar como cada um ocupou a área do Guarituba e como conquistou a moradia em que vive;

c) casa: investigar sobre o processo de construção da moradia e sua relação com a vida cotidiana da família;

d) vida cotidiana e cotidianidade: investigar a rotina de atividades que o entrevistado e sua família realizam no dia a dia para o trabalho, estudo, lazer e consumo, procurando observar como se apropriam do espaço por intermédio dessas atividades;

e) as ações do Estado: investigar a percepção dos moradores quanto às recentes transformações do Guarituba (urbanização, casa nova, regularização fundiária) e de que forma afetaram seu espaço cotidiano.

\section{Da análise do cotidiano vivido a questões importantes ao planejamento}

A investigação realizada no Guarituba, tendo em vista o cotidiano ali vivenciado, trouxe à superfície questões importantes para o planejamento urbano, que se destacam por evidenciar o modo como a desigualdade social e urbana afeta uma parcela da sociedade que luta diariamente, por meio de arranjos improváveis, contra a precariedade. Indo além, algumas das situações analisadas revelaram a ausência do poder público, demonstrando que certas ações que se fazem necessárias não dependem de recursos, mas de atitude diante da realidade que se mostra ao se analisar "de perto" e "de dentro" o cotidiano vivido pela sociedade. As questões levantadas pela pesquisa contribuem com o objetivo anunciado de aprofundar perspectivas de atuação no campo do planejamento urbano a partir do vivido.

Apresentam-se, a seguir, cinco questões que se mostraram mais importantes e prementes ao planejamento urbano.

\section{A historicidade no cotidiano moderno: simultaneidade de tempos e espaços}

O Guarituba atual, que se observa "de fora", encontra-se estruturado por três vias principais nas quais se concentram o comércio e serviços públicos e privados: as ruas Herbert Trapp, Betonex e Juri Danilenko (Figura 2). É visível a mudança na dinâmica urbana relativa ao desenvolvimento local provocado pelos projetos de urbanização da última década. 0 comércio e os serviços privados ou públicos de suas três principais avenidas têm se transformado pela incorporação de tempos e conteúdos de maior diversidade. Evidencia-se uma centralidade de funções, ainda que de influência local, atuando na produção do espaço, fundada na valorização do solo do Guarituba.

A dinâmica e a linguagem paisagística se identificam com outros espaços valorizados da metrópole em função das possibilidades abertas ao consumo acessível, como um renovado motivo para que mais pessoas utilizem esses espaços e um ritmo que se revela pela organização do espaço cotidiano do repetitivo, da programação da cotidianidade.

Contudo, foi possível constatar também que, ao mesmo tempo, o cotidiano de muitas famílias é ainda marcado pela inclusão precária, violência, vulnerabilidade e injustiça social e espoliação, imagem desde há muito tempo associada ao Guarituba. Em realidade, 
tal contradição pode ser avaliada segundo a perspectiva de DaMatta (1997, p. 30) de acordo com o qual a sociedade moderna brasileira possui de singular o fato de ter muitos espaços e muitas temporalidades convivendo simultaneamente no cotidiano, e isto na medida em que "tanto o tempo quanto o espaço são invenções sociais", ou seja, construídos pela sociedade dos homens.

Martins (2014, p. 175) afirma que, para Lefebvre, esse espaço é tridimensional, e o homem comum e cotidiano se move nesse espaço do percebido, do concebido e do vivido, conformando um sistema formado por uma totalidade aberta e não fechada. Ainda segundo o autor, por ser aberta, o possível pode ser elucidado na interpretação desses espaços, a partir do método desenvolvido por Lefebvre, denominado regressivo-progressivo (Martins, 2013, pp. 105-106). Neste, temporalidades desencontradas e coexistentes podem ser recuperadas pela elucidação do "percebido pelo concebido teoricamente" e da definição das "condições e possibilidades do vivido". As possibilidades apresentam-se pelas contradições sociais dos desencontros, que não são somente confrontos de interesse entre categorias, mas também do desencontro de tempos. "Porque é o desencontro das temporalidades dessas relações que faz de uma relação social em oposição a outra a indicação de que um possível está adiante do real e realizado".

Analisado à luz dessa descoberta de Lefebvre, o conjunto das 39 entrevistas realizadas possui a qualidade de demonstrar essa simultaneidade e interação de temporalidades desencontradas, contando aspectos da historicidade da ocupação do Guarituba no intervalo da década de 1960 até os dias atuais, com contradições dialéticas entre o antigo e do novo; características rurais e urbanas; legal e ilegal; públicas e privadas; realidade local e metropolitana.

0 antigo e o novo coexistem no espaço moderno constituído pelo processo de urbanização e pela produção de novos modos de produção e apropriação do lugar lado a lado aos donos de chácaras alemães ou ucranianos, antigos produtores de leite, que vieram na década de 1960 em substituição aos primeiros colonos, em sua maioria menonitas. ${ }^{5}$ Muitos deles ainda permanecem ao longo da rua Pastor Adolfo Weidmann, alheios em seus espaços. Em suas falas, dizem que nada mudou, pois continuam a viver em suas terras como antes, sem relação com outros lugares e, ainda, segundo dizem, protegidos pela legislação que não permite que a urbanização avance sobre suas áreas, pois vivem em uma região de manancial de abastecimento.

$O$ antigo e o novo coexistem também no traçado do Guarituba, nas lembranças dos moradores antigos que, ao olharem para espaços e vias, enxergam o antigo campo de futebol ao invés do posto de saúde; as vacas que deixavam suas marcas nos carreiros da rua Betonex e da rua Pastor Adolfo Weidmann (hoje pavimentadas); a antiga ponte de madeira do rio Iraí; os arrasta-pés na casa do velho Heinrich, onde hoje se comercializa o baile do pato; os peixinhos nas nascentes da área de várzea; e o solo fofo e turfoso.

Lembram-se de quando vieram para viver no Guarituba, como no caso de um dos primeiros moradores da Planta Santa Lúcia, no final da década de 1970. 0 entrevistado conta que foi chamado de louco pela família, quando tomou a decisão de finalmente 
construir sua casa no meio do nada. Ele nos conta que anos depois começou a chegar mais gente: "é como jogar um arroz no terreno e encher de passarinho".

Logo, um dos donos de chácaras cedeu espaço e implantaram a primeira igreja católica na rua Betonex. Era uma barraca de madeira onde se rezava missa, faziam catequese, primeira comunhão e festas religiosas. $E$, além da religião, os laços de vizinhança entre os moradores dos loteamentos e os donos de chácaras foram fortalecidos também pelo futebol.

Com o aumento dos ocupantes nos loteamentos, iniciaram-se os conflitos com os produtores rurais da região, pois as vacas viviam soltas por toda a extensão de terras do Guarituba, desde a avenida Pastor Adolfo Weidmann até a rodovia PR 415, sobre os lotes coloniais subdivididos, na década de 1950, e que foram logo sendo transformados em loteamentos, a partir da década de 1960.

Quando ia ver tinha mulheres tirando leite das vacas. Chegaram a matar vaca que estava esperando bezerrinho e largavam tudo lá, só tiravam as partes boas. [...] Tinha plantação de pêssego, teve que desfazer porque o pessoal invadia e roubava os insumos que usava. (E23, 2016)

Pode-se verificar a coexistência do rural com o urbano, sobretudo, no interior das próprias famílias que passaram a ocupar os loteamentos do Guarituba, legal ou ilegalmente. Provenientes da "roça", trouxeram consigo hábitos como a criação de animais, horta e formas de sobrevivência de lugares desprovidos de infraestrutura urbana. Muitas dessas famílias mantiveram a tendência de permanecer em suas casas, conectadas a seus antigos costumes e tradições.
Verifica-se que os mais modernos, por sua vez, estabelecem com a casa uma relação de local, de refúgio da cotidianidade, do repetitivo do dia a dia de trabalho ou do mundo cheio de adversidades do lado de fora de sua moradia, seja ela legal ou ilegal. Não significa, no entanto, que vivam isoladamente, mas que possuem, a partir de sua moradia, a oportunidade de perceber o mundo pelo código da casa e da família (privado), para conviver, conforme DaMatta (1997), com o código da rua ou aquele do legalismo jurídico (público) que produz uma fala totalizada e impessoal no conjunto da sociedade.

Segundo esse conceito, a rua consistiu, no contexto analisado, na resultante da atuação dos órgãos públicos que, em função da proteção dos mananciais, ameaçou famílias de despejo e privava de infraestrutura os moradores das partes leste e oeste do Guarituba nas décadas de 1980 e 1990. As imobiliárias continuavam a vender as propriedades, pois isto não era ilegal, uma vez que os loteamentos foram aprovados legalmente. 0 ilegal era que fossem ocupados, pois era área de manancial protegida pelo Estado, e os novos proprietários não sabiam disso. 0 ilegal era também a grilagem de terras.

Foi em 1994 que ocorreu a grande ocupação "por invasão" na área do jardim Orquídeas, "chegaram mais de duas mil famílias naquela invasão. Escurecemos e amanhecemos com a ocupação" (E3, 2016). Segundo essa liderança local entrevistada, em função do medo da desapropriação, muitos perceberam, diante das novas ocupações, que a luta pela moradia era ainda maior, ou seja, que o interesse dos que tinham registro e dos que não tinham era o mesmo: ter um lugar para morar. 
Na década que se seguiu, após 1994, 0 Guarituba cresceu exponencialmente. Os moradores antigos relatam que os primeiros benefícios, como a chegada da luz e da água em alguns pontos e também a construção de escola e do posto de saúde, que os deixaram felizes no início, não foram suficientes para atender à demanda por serviços básicos, na medida em que aumentava o número de famílias de renda muito baixa. O Estado, em função da condicionante ambiental estabelecida pela preservação dos mananciais, não dotava as áreas ocupadas ilegalmente (com ou sem registro de imóveis) com infraestrutura e, dessa forma, cresciam sem luz e sem água, muito menos esgoto. Assim, a informalidade aumentou com a espoliação urbana, aumentando, também, os problemas da população residente em tais espaços periféricos da metrópole.

Na década de 2010, as formações iniciais ao leste e ao oeste do Guarituba foram finalmente interligadas pela rua Juri Danilenko, pavimentada e urbanizada em 2010, através do Prau/Guarituba (PAC 2007). Esse plano previu, dentre suas ações, a construção do Conjunto habitacional Madre Teresa de Calcutá, com recursos do PAC (2007), no qual as famílias que viviam em área de risco de enchentes ou em condições precárias de moradia no Guarituba e locais próximos foram reassentadas em 2012 e 2013.

Destaca-se que, em consonância com a expectativa gerada por esse plano, ocorreu, em outubro de 2010, a Ocupação Olga Benário, com mais de cem famílias, numa área de aproximadamente dois hectares do Guarituba, localizada próxima à rodovia PR 415. Sendo despejadas dois meses depois (2/12/2010), a partir da determinação de desocupação pela justiça, 49 famílias que declararam não ter para onde ir foram alojadas no ginásio da Escola Municipal Heinrich de Souza. Ali permaneceram por cerca de 80 dias, quando foram finalmente retiradas pela Polícia Militar, no dia 18/2/2011, vindo a construir "seus barracos na calçada, do outro lado do muro da escola" (PSOL, 2011).

Constata-se que, diante do início de políticas públicas de investimentos no Guarituba e com a entrada do governo de esquerda no Brasil, a Ocupação Olga Benário representou uma denúncia da população em relação à continuidade do problema da moradia, atrelada às condições da produção do espaço da cidade e da metrópole como um todo. Tendo sido retirados daquele lugar que vieram reivindicar, voltaram a pulverizar-se no espaço da invisibilidade, demonstrando que o governo que ali se encontrava representado pelo setor habitacional municipal, estadual e federal manteve distância do problema da demanda por habitação de baixa renda.

Pelo acima exposto, a realidade observada "de perto", no Guarituba, revelou a importância de se planejar a partir do plano do lugar, na medida em que a coexistência de espaços e tempos diversos e, sobretudo, de suas contradições (antigo e novo, rural e urbano, legal e ilegal, público e privado, local e regional), indica o risco de empreender ações que levam em conta o espaço percebido e concebido, mas que contém armadilhas por não perceber o vivido.

Pode-se concluir que o planejamento praticado no Guarituba (plano metropolitano, plano municipal e também o Prau/Guarituba), ao seguir um modelo definido dentro dos órgãos públicos, respaldados pela legislação e instrumentos existentes, em especial a de proteção dos mananciais, pode ter deixado de 
considerar problemas e contradições vistos a partir da historicidade do lugar, tendo como base o vivido no cotidiano dos moradores. Ao agir assim, o planejador urbano assumiu sem questionar a lógica capitalista de urbanização da metrópole, corroborando um processo de desigualdade e segregação social, assentado na valorização crescente do solo e da propriedade e gerando situações que depois deverão ser enfrentadas/solucionadas por ele mesmo.

\section{Quando a urbanização é necessária, mas insuficiente}

A investigação realizada, tendo em vista a cotidianidade nos dois lugares do Guarituba - o conjunto habitacional Madre Teresa de Calcutá (CHMTC) e o jardim Orquídeas -, mostra dois exemplos distintos de como o Estado, ao mesmo tempo que atuou em melhorias para a sociedade, implementando a urbanização de espaços, demonstrou insuficiência nas ações de urbanização promovidas - nesse caso, por meio de um plano com recursos do PAC (2007), ou seja, o Prau/Guarituba.

No Conjunto habitacional

Madre Teresa de Calcutá - CHMTC

A implementação atendeu ao remanejamento e à realocação de famílias localizadas em áreas de risco ou vivendo em condições precárias em 694 unidades habitacionais no ano de 2012. Nesse caso, constatou-se que a construção do conjunto habitacional no Guarituba significou um movimento cotidiano das pessoas em direção à superação da precariedade absoluta em que viviam, por meio da aquisição de um lugar urbanizado para morar.
De fato, a possibilidade de residir em um conjunto habitacional urbanizado permitiu superar a ausência de infraestrutura básica, em especial a energia elétrica clandestina e a falta de água. A lembrança que predomina no imaginário de todos é a forma como tinham que percorrer o trajeto até suas casas, geralmente um "carreirinho" até o ponto de ônibus ou escola, numa lama preta na qual afundavam o pé, principalmente nos dias de chuva.

Considera-se que, a partir das ações do Estado, um importante passo foi dado na direção da obtenção de condições básicas de moradia. Baseado no pensamento de Locke e Hegel sobre direitos de propriedade, Holston (2013, p. 158) sustenta que o direito de propriedade fundiária é importante para os indivíduos porque, acima de todos os direitos, assegura a sua liberdade.

A contradição é que, no sistema capitalista, a propriedade está acima do direito de morar, e, nesse contexto, um indivíduo sem lugar onde residir se encontra em posição diferenciada e desprivilegiada em relação a um proprietário de terra. Sendo assim, possuir uma propriedade constitui-se em uma desigualdade na linha de partida, tornando a liberdade uma função da propriedade. Holston (ibid., p. 159) afirma, assim, que "um governo responsável pela liberdade de seus cidadãos deve garantir a propriedade como uma de suas principais obrigações".

Contudo, com base no estudo, foi possível verificar que a urbanização e a obtenção de uma casa são tanto fundamentais como insuficientes para a superação das injustiças. A investigação realizada demonstrou que muitas famílias se encontram também na linha de partida, no que se refere à garantia de acesso 
ao necessário para viver a cotidianidade, enquanto produto organizado e programado do conjunto da sociedade. Alguns exemplos revelam essa situação:

- sob a perspectiva das condições de investimentos na nova casa, constatou-se que seis dos entrevistados no CHMTC trabalham na informalidade, sem garantia de uma renda mensal. E embora dois deles tenham murado e realizado alguma reforma, para estes, reservar dinheiro para isso significa muitas vezes deixar outras prioridades de lado, como se alimentar adequadamente ou pagar as contas de luz e água. Estas famílias são as que se encontram também temerosas com relação ao pagamento que deverão efetivar durante dez anos para possuir o registro do imóvel;

- em relação ao lugar onde realizam as compras para o dia a dia, verifica-se que também nesse caso são nítidas as limitações decorrentes do padrão financeiro das famílias. Aqueles que possuem a oportunidade de integrar-se à cotidianidade moderna do trabalho (no ritmo do trabalho fixo e da rotina diária, condição designada ao homem moderno da sociedade do consumo) consomem com frequência os produtos dos novos espaços urbanizados, dos supermercados das vias principais, onde se encontra de tudo. Contudo, a precariedade de muitas famílias evidencia-se na preferência em permanecer em casa sem gastar, comprando apenas aquilo de que precisam e com os recursos que possuem nesse dado dia. Outros nem saem de casa, pois é comum realizar a compra com os vendedores ambulantes de cestas básicas, com os quais possuem a vantagem de poder pagar depois ou em duas vezes;
- a maior parte dos entrevistados respondeu que há muito tempo não fazia compras de roupas, podendo ser constatado, também, que famílias com crianças recebem ajuda da igreja;

- ao contrário do que possa transparecer pelo desenho do conjunto, que destina amplos espaços para o automóvel, são poucas as famílias que possuem carro; as largas vias que circundam os três grandes espaços públicos centrais permanecem, a maior parte do tempo, vazias. É interessante observar que ter um carro em espaços com precariedade e vulnerabilidade social significa ser solicitado a todo momento para prestar ajuda à comunidade;

- a infraestrutura urbana e a construção de um novo posto de saúde não minimizaram a ausência do Estado no atendimento básico da saúde, pois a demanda continua a ser muito maior do que 0 atendimento existente. 0 mesmo acontece com a educação. Além disso, verifica-se certa preocupação entre alguns entrevistados com relação à qualidade do ensino nas escolas locais.

Tais evidências ressaltam, dessa forma, o aspecto da vulnerabilidade social como um problema estrutural. Nessa direção, de acordo com Volochko (2011), as transformações para uma possível inclusão de habitantes na cotidianidade ocorrerão tendencialmente na forma do cotidiano desigual, "como reprodução necessariamente desigual e contraditória do capitalismo" (ibid., p. 210). ${ }^{6} \mathrm{E}$, sendo assim, a forma do cotidiano desigual é a cotidianidade que se realiza de forma contraditória, conforme constatado na investigação de "dentro" do CHMTC, como "presença-ausência do Estado, como realidade-representação" (ibid.). 


\section{No jardim Orquídeas}

A diferença do jardim Orquídeas com o CHMTC consiste no fato de que muitas famílias ali já contavam com condições básicas de vida resolvidas quando se iniciaram as ações do governo em 2007, pois a ocupação existia desde a década de 1980. Porém, outras tantas que vieram ao longo do tempo ocupando "por invasão" enfrentavam ainda um cotidiano marcado pela desigualdade e pela dificuldade em se inserir em um mercado de trabalho formal (no ritmo do trabalho fixo e da rotina diária, condição designada ao homem moderno da sociedade do consumo).

Se o cotidiano desigual é uma constatação realizada graças à investigação do CHMTC visto "de dentro", o jardim Orquídeas constitui uma representação evidente desse modelo somente com a observação "de perto" e de passagem. Apesar de já estar previsto no plano de que as obras de infraestrutura de drenagem no jardim Orquídeas seriam efetuadas ao final do cronograma, houve um grande atraso de implementação do PAC II/2007; e, em 2015, quando esta pesquisa foi iniciada, era evidente o abandono das ações do governo, o que também foi identificado nas falas dos moradores em 2016.

No jardim Orquídeas, a realidade demonstrada por trás do que alguns técnicos chamaram de "descompasso das obras" é cruel. Conforme se constatou, a informação constante no PTTS/2010 de que a rede de esgotamento sanitário se encontrava instalada não era verdadeira. As casas não estavam ligadas à rede de coleta principal, o que acarretou, diante do atraso no prosseguimento e finalização das obras estruturais, um processo reverso à intenção de melhoria da qualidade de vida: ligações clandestinas de esgoto foram realizadas, ao passo que aumentava a densidade populacional e de edificações no lugar - impulsionadas pelo anúncio do PAC/2007 e do programa "Direito de Morar". Essas ligações, associadas aos inúmeros aterramentos que elevaram consideravelmente o nível da rua e dos novos lotes, tiveram o efeito de reproduzir um problema existente e que já tinha ocorrido em outras regiões do jardim Orquídeas: as enchentes e o refluxo de esgoto para dentro das casas.

Aponta-se que a insuficiência nas ações de urbanização, nesse caso, refere-se à falta de um trabalho social para a implementação das ações de infraestrutura no jardim Orquídeas - assim como ocorreu com o processo para a implementação do CHMTC - que pudesse minimizar parte dos transtornos ocasionados às famílias pelas obras.

\section{Projeto fora do lugar desconsidera evidências há muito tempo estabelecidas}

A investigação sobre o cotidiano, tendo em vista as entrevistas realizadas junto aos moradores do CHMTC, possibilitou apreender o contraditório com relação às formas de apropriação e produção do espaço pelos moradores, mediante o determinismo projetual de técnicos e instituições. Essa contradição está presente na concepção do espaço pelo Estado, que tenta reproduzir o modo de vida da cotidianidade moderna, como forma de realizar a inclusão social. O Estado, com o compromisso de reduzir as desigualdades historicamente constituídas, acaba por evidenciar a falta de percepção de urbanistas e gestores urbanos sobre a realidade vivida, tendo como 
consequência uma paisagem adversa em relação ao idealizado, cujo projeto tinha o objetivo de humanizar o espaço.

De fato, como princípio norteador, o projeto do CHMTC propunha uma escala próxima ao morador, com base em um desenho concebido para promover as relações de vizinhança e diversificar o modelo das casas (geminada, isolada, adaptada para deficientes e sobrado). Ferraz (2016) relata que, com o intuito de aproximar-se da escala humana, foram criadas ruas internas em cada quadra, de uso dos moradores, separando o pedestre do carro. A ideia era que essas ruas promovessem maior relação entre os vizinhos, tendo sido concebidas para serem iluminadas, sem muros e utilizadas conjuntamente entre as famílias. Sendo assim, a parte frontal das casas foi voltada para essa via interna e a parte posterior para a via local, por onde entrariam os veículos automotivos. Além das ruas internas, observa-se que algumas das vias destinadas a carros não possuíam saída, o que induzia sua utilização prioritária para pedestres e crianças. Com função similar, foi denominado "eixo verde central" o grande espaço que deveria ser apropriado pelos moradores para eventos cívicos e de lazer. 0 entrevistado conta que receberam ajuda de professores da Universidade de Pádua da Itália na concepção do conjunto, que resultou na interação de aspectos ambientais, das pessoas e da paisagem, "podendo-se ver o ambiental da serra do mar e dos campos".

Contudo, logo nos primeiros anos do processo de ocupação e apropriação do espaço da casa e da rua pelos moradores, ficou evidente que o modelo idealizado pelos urbanistas projetistas era inadequado, caracterizando-se como um projeto fora do lugar. Pode-se dizer, resguardadas as boas intenções dos projetistas, que a concepção utilizada de "espaços humanizados" estava fadada ao fracasso desde o início, pois o domínio do tráfico e da violência era evidente no Guarituba desde a década de 1990. O medo do convívio diário com o tráfico e a morte se constituiu num dos aspectos comuns presentes em todas as entrevistas.

Ressalta-se que não é novidade a conclusão desta pesquisa, considerando-se as críticas e análises existentes sobre os conjuntos habitacionais no Brasil desde a década de 1960. No entanto, verifica-se que tais evidências não foram consideradas como condicionantes projetuais. Pode-se inferir que certo autoritarismo prevaleceu, por intermédio da reprodução de práticas de projetos (com contribuição de profissionais vindos da Europa), definindo, em relatórios e desenhos de prancheta, o tratamento paisagístico ou a forma como as relações de vizinhança e a segurança das famílias ocorreriam.

Tal determinismo projetual se mostrou especialmente grave no CHMTC, com relação à definição de vias internas às quadras (Figura 3). Com o problema da violência e do tráfico, muros foram sendo erigidos, e a paisagem resultante demonstra a imagem da negação do espaço público da rua, como se as famílias voltassem suas costas para a via interna. Essas vias foram transformadas em pontos de vendas de drogas e rotas de fuga dos traficantes, além de evitadas pelos moradores locais.

Apesar de o medo ter sido o motivo fundamental de se erguerem os muros nas ciclovias, estes também são associados ao fato de que as casas, sendo muito pequenas, não constituíam espaço suficiente para manter a privacidade das famílias sem que a rua, com suas leis e imposições (instituídas ou não), 
Figura 3 - Via interna antes (2012) e depois (2016)
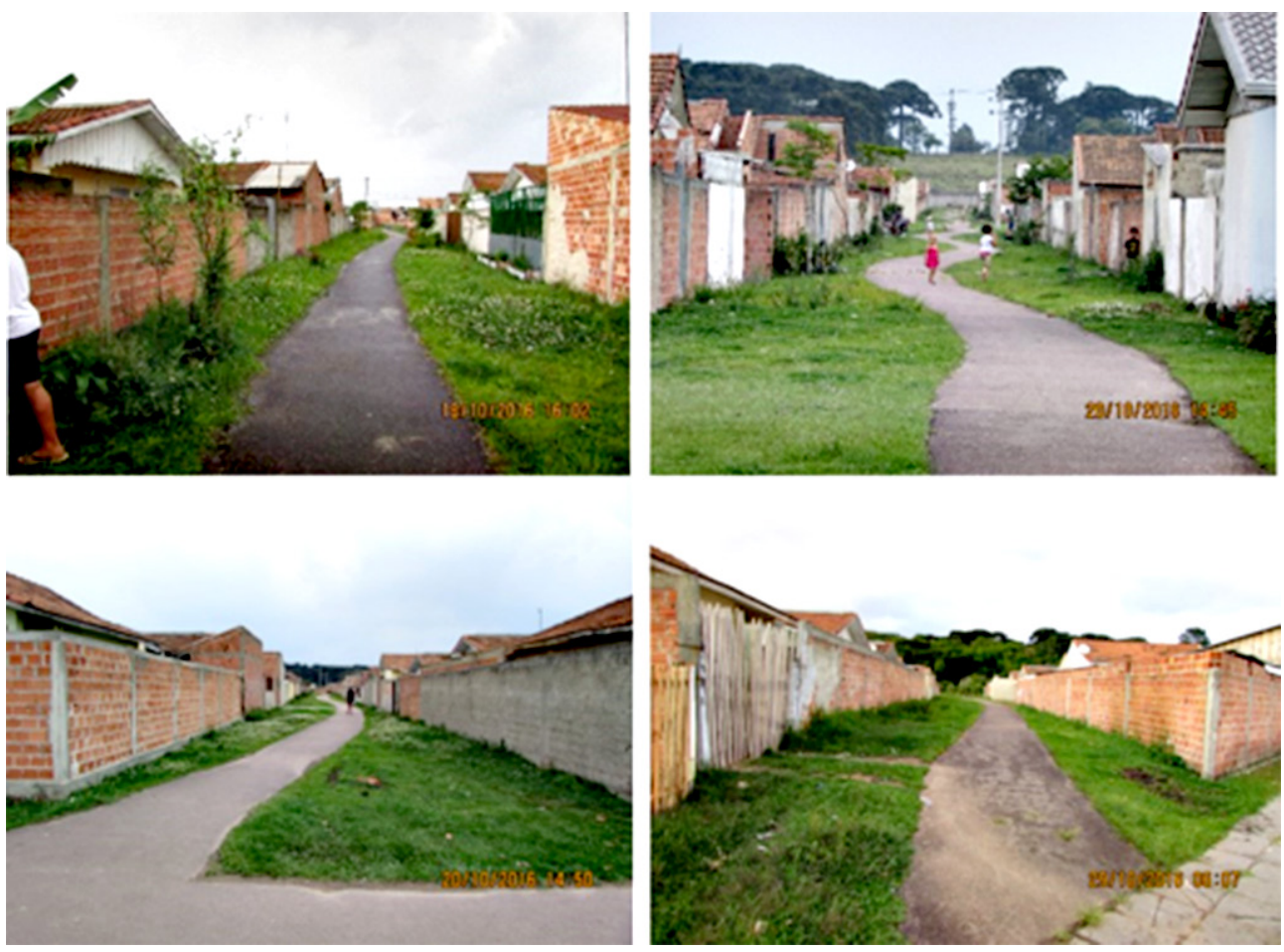

Fotos: autora, em 2016.

violassem o espaço do lar. Para uma parte dos moradores, as diferentes tipologias de casas não se traduziam em qualidade; antes significaram, para a maioria que recebeu casas geminadas, a impossibilidade de aumentar o espaço interno de suas moradias.

A definição dos territórios das gangues rivais dentro do conjunto não se realizou sem que houvesse muitas mortes. Os sobrados tornaram-se torres de vigilância dos traficantes e as vias internas locais, em pontos de venda dos "aviões". Todos sabem que, ao cair da tarde, as vias internas são intransitáveis e que, além disso, servem como caminhos de fuga quando a polícia aparece: moldadas pelos muros, são todas iguais; pulando-se os muros para dentro de um quintal, dificulta-se a perseguição dos policiais.

Verifica-se que o desenho do conjunto destinava amplos espaços e vias para a mobilidade do automóvel, realizando uma conciliação duvidosa com a prioridade dada ao pedestre nas ruas internas. 0 projeto traz à lembrança o modelo haussmaniano de Paris, cujas largas vias foram projetadas para a passagem do exército de Napoleão em caso de guerra; nesse caso, para o policiamento do conjunto.

Ideias fora do lugar, um projeto fora do espaço e do tempo do Guarituba. 


\section{Valorização imobiliária pari passu aos problemas da inclusão social precária}

Com uma paisagem aparentemente homogênea pela urbanização e modernização de certos espaços comerciais, residenciais e de serviço no Guarituba, destaca-se também a crescente valorização imobiliária, com substituição do valor de uso da terra (que cumpre uma função social) pelo valor da troca, quando a propriedade passa a valer mais.

O problema da valorização imobiliária que redunda na inclusão social precária constitui tema amplamente discutido e avaliado na crítica ao planejamento urbano. Não se pretendeu aprofundar essa crítica a partir desta investigação, mas destacar que o estudo realizado a partir do cotidiano aponta para o fato de que, com poucos recursos e tempo, foi possível realizar um diagnóstico da situação atual que dados quantitativos não são capazes de apreender, a curto prazo, com relação a esse tema. Três situações servem para ilustrar essa afirmação.

A primeira delas refere-se ao fato de que, embora para alguns, no Guarituba, a terra tenha se tornado mercadoria rentável pela sua valorização, para muitos outros, ainda predomina a situação de insegurança sobre a posse da propriedade. Tal insegurança foi verificada no temor que existe entre muitas famílias de se tornarem inadimplentes e perderem suas casas, caso não consigam efetuar os pagamentos das prestações das moradias no conjunto habitacional.

São famílias que subsistem no limite de sua economia e, para elas, pagar um aluguel ou a parcela da possessão de um imóvel significa deixar de consumir o básico: alimentação, saúde, educação, luz ou água. Apesar de residirem sob um teto construído com recursos do governo, vivem a mesma situação de precariedade constituída pela falta de condições básicas de vida. Isto mostra que as ações e obras do governo significam uma inclusão precária dessas famílias na sociedade.

Da mesma forma, outros que não adquiriram um imóvel no conjunto habitacional, mas a promessa de regularização fundiária, vivem o temor de que isto não se concretize pela impossibilidade pagar por tal serviço. Recentemente, no final de 2016, a Cohapar realizou convênio com imobiliárias para promover a regularização fundiária do Guarituba. Um dos moradores entrevistados que aderiu à proposta de regularização conta que a imobiliária cobra pelo serviço o preço de "R\$4.500,00 à vista, podendo esse valor ser pago em até 60 vezes com parcelas de $\mathrm{R} \$ 100,00$ ". Ele optou por regularizar em 12 meses e complementa: "Quem não tem dinheiro não faz".

Outra situação representativa do processo agressivo de especulação imobiliária em andamento no Guarituba é o caso da entrevistada que assinou um contrato de compra e venda de sua propriedade de uma imobiliária, na rua Juri Danilenko, no final da década de 1980. As prestações do contrato: 60 vezes para, então, efetivar a compra com o registro de imóveis. Pagou 46 prestações, "aí como alguns não pagavam nada e outros pagavam muito menos e como eu andei numa crise, eu parei de pagar". Em 2014, outra imobiliária bateu à sua porta. Descobriu que a imobiliária com quem fechara o contrato havia vendido a propriedade inadimplente para outra e que agora esta queria o imóvel, alegando que era 
uma "invasora" desde 2009. Na primeira audiência com o juiz, um acordo para "terminar de pagar para reaver o imóvel" não pôde ser realizado, porque o outro proprietário, seu irmão, não estava presente. Para a segunda audiência, preparou-se, contratando um advogado para o qual entregou todos os originais de seus documentos de recibos de pagamentos e contratos. Nessa audiência, esse advogado não compareceu e teve que concordar em sair do lugar, recebendo em troca um lote em outro local. Nunca mais conseguiu reaver os documentos que entregou, o advogado alega nunca os ter recebido.

Os três casos acima ilustram situações de famílias que, no limite da precariedade, convivem com os problemas ocasionados pela valorização da terra. Demonstram situações evidentes da necessidade de ação de políticas públicas inclusivas, com a presença do Estado junto a situações específicas que se identificam pela incapacidade de parte da sociedade de alcançar os benefícios dos projetos e programas estabelecidos por essas políticas. Destaca-se, dessa forma, que o Estado se torna ausente quando trata a desigualdade social a partir de programas que consideram a sociedade como se ela fosse homogênea. As evidências acima demonstram que ela não é.

\section{Em destaque para o planejamento: a superação de limites}

Verifica-se que, diante da ausência do Estado em questões primordiais para grande parte do Guarituba, a vida cotidiana de muitas pessoas resume-se na superação diária de limites estabelecidos por ações do Estado. Esse movimento de superação constante constitui-se no mais importante cenário identificado pela investigação no CHMTC e no jardim Orquídeas.

O espaço interno do CHMTC e do jardim Orquídeas pode ser analisado a partir do seu contraste com o espaço externo, ao passo que existe uma interação cotidiana entre eles. 0 movimento repetitivo diário de estudantes pelas calçadas da rua Juri Danilenko, na entrada e na saída das escolas, não deixa dúvidas de que o CHMTC possui um elevado número de crianças. Ao percorrer o conjunto de carro, pelas vias internas e externas, observa-se, contudo, que quase não há crianças nas grandes áreas públicas no horário de contraturno das aulas.

Passando a entender a lógica de dominação do território pelos traficantes, verifica-se que, nos interstícios permitidos de espaço e de tempo, as crianças utilizam inteligentemente a rua, em horários e locais específicos - geralmente na rua larga e não interna, nos cantos das quadras voltados para a praça e não na praça (Figura 4). Sabem que devem voltar para dentro de casa antes do anoitecer e que, nesses horários, devem evitar as ruas internas. As crianças, no contraturno, possuem uma vida cotidiana limitada pelas regras definidas pelos grupos de traficantes na rua. Obedecem a elas e aprendem, desde cedo, que esses códigos garantem a sua sobrevivência no local.

Observou-se ainda, nos depoimentos dos entrevistados, a indicação de espaços como se fossem separados por uma linha. A relação de "dentro e fora" do conjunto é exposta por uma linguagem de segurança para os que vivem perto da rua Juri Danilenko e de insegurança em seu interior. Da mesma forma, o limite municipal entre Pinhais e Piraquara, situado 
Figura 4 - O espaço da criança

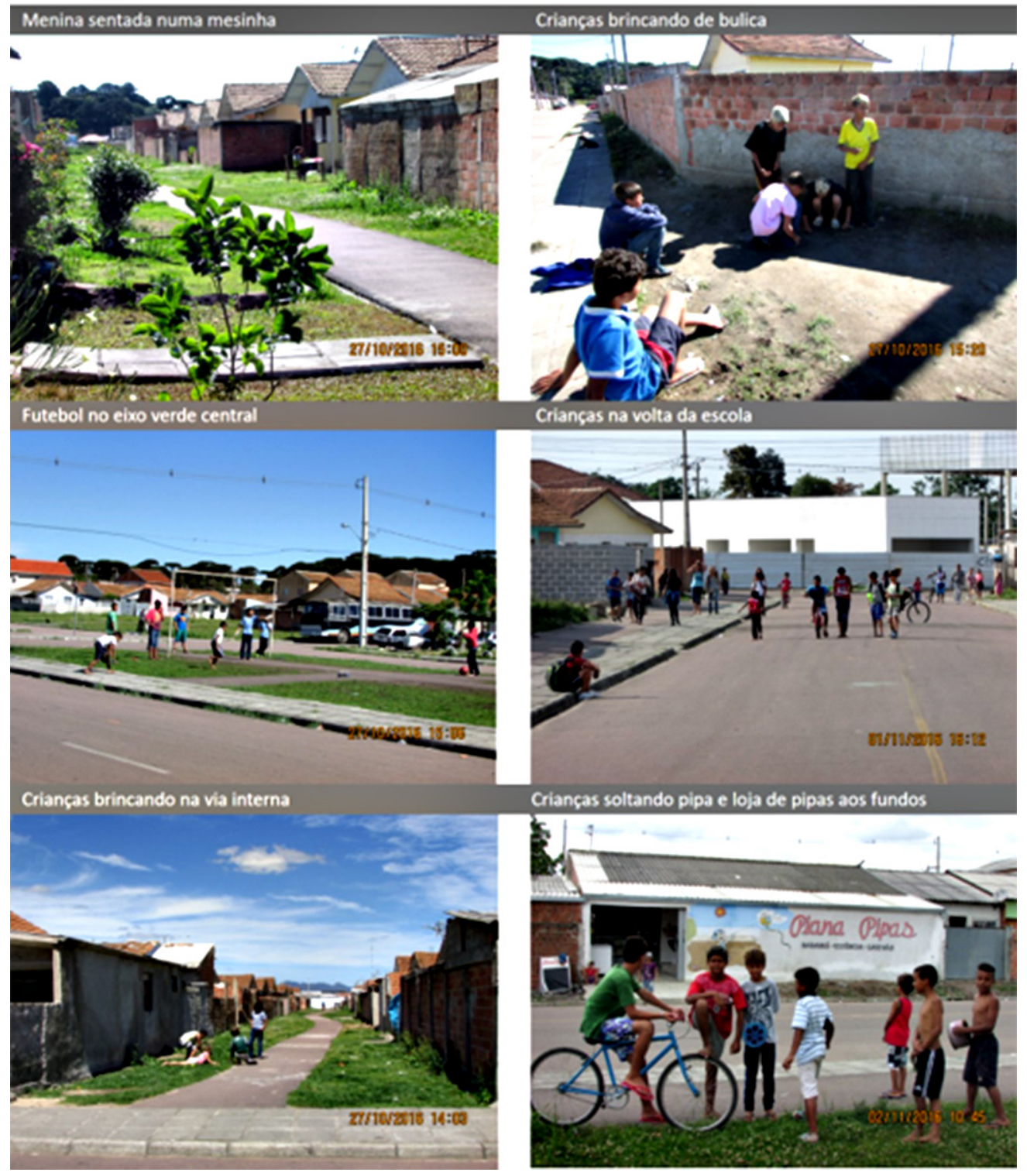

Fotos: autora, em 2016. 
no contorno oeste do Guarituba, estabeleceu-se pela separação de privilégios para quem vive do lado de lá em relação aos que vivem do lado de cá, sem que se possa separar os laços históricos, familiares e de distância que unem os espaços. A separação/interação ficou evidente também na historicidade do movimento constante de vizinhos vindos de fora em relação aos que estavam dentro nas várias épocas e ocupações que ocorreram ao longo do tempo, passando a dividir os mesmos problemas, impostos geralmente pelas leis de ocupação restritivas do lugar.

A dimensão da cotidianidade revela, ao planejamento, por meio desses movimentos de superação e de interação, a necessidade de se pensar pelas contradições do vivido, da totalidade e do significado do Guarituba no processo de reprodução da RMC. Vale a pena repetir o que disse Lefebvre: "[...] a dificuldade consiste em que é preciso mostrar que os fragmentos não se dispersam e não se isolam, mas convergem num projeto de transformação do mundo" (apud Martins, 1996, p. 13).

A falta de perspectiva nos discursos das famílias apontou para a importância de se observar para além dessa aparente passividade, permitindo entender o que quis dizer Martins (2013) ao se referir à realidade do homem simples brasileiro, que somos todos nós. A partir de casos de extrema precariedade do Guarituba, esse homem simples revela a ironia da irracionalidade que se instala nas ações do governo ao planejar, tendo como referência uma cotidianidade moderna, sem a necessária aproximação com as contradições nesse tempo e nesse espaço. Revela, ainda, que, diante da presença-ausência do Estado, a cotidianidade é vivida pela constante interação dos diversos espaços e temporalidades, na negação e na superação, com continuidades e descontinuidades, com justiças e injustiças, vida e morte, revelando o anômalo e o inacabado da modernidade brasileira.

Martins (ibid.) destaca que, tanto para Lefebvre como para Heller, essa constante interação implica, diante do banal e do insignificante, o surgimento de momentos de "elevação acima da cotidianidade", instantes superiores e criativos, o que significa, em poucas palavras, a possibilidade de "mudar a vida" e, também, de "mudar de vida". Enxergar essa possibilidade oportuniza uma forma de empoderamento da sociedade, de modo a se responsabilizar pela gestão de suas necessidades, tomando de volta do Estado direitos confiscados por este ao assumir a lógica capitalista da urbanização, produzindo a desigualdade social.

A partir da investigação realizada, observaram-se formas criativas de superação, ligadas à necessidade de sobrevivência e, por isso, conectadas a laços de solidariedade e de vida cotidiana. É o que se observou na atitude das mulheres que, para ficarem ao lado de seus filhos em casa, procuram formas alternativas de incrementar a renda da família, realizando bazares de roupas e cuidando de crianças do bairro. Uma das mulheres passou parte da sua vida vendendo produtos trazidos por mascates, sem nunca sair do Guarituba; outra aumentava a renda familiar descascando alho em casa para uma empresa.

Da mesma maneira, encontraram-se os jovens que procuram caminhos alternativos para as condições impostas pela precariedade, desafiando a péssima qualidade da educação local, que tende a dificultar a entrada em uma universidade. Verificaram-se, ainda, formas de superação da ausência do Estado, construídas no tempo e no espaço da intrincada estrutura 
da vida cotidiana, a qual, de acordo com Heller (2014), é heterogênea, complexa, "feita de momentos de espontaneidade, probabilidade e possibilidade, economicismo, pragmatismo, ultrageneralização, precedentes, imitação e entonação" (p. 34). E por isso mesmo, carregada de alternativas e escolhas.

As formas criativas de superação estão relacionadas também com a definição de Lefebvre de vida cotidiana, já que, na complexa dimensão da programação da vida pela cotidianidade moderna, o cotidiano desigual estabelece-se para muitas famílias por movimentos que têm como respaldo a procura por um "habitar". Esta é a situação dos moradores que residem em sua "casa como um poeta", onde a precariedade impõe necessariamente o valor de uso e não o consumo como condição, conforme pôde ser constatado na investigação realizada. Esses moradores parecem compreender o que diz Lefebvre, quando revela que a cotidianidade resultante da programação da vida cotidiana pelo capitalismo moderno abriga a redução da vida cotidiana. Enquanto frutos da cotidianidade moderna desigual, valorizam a vida cotidiana que possuem, lutando em seu dia a dia, utilizando arranjos improváveis, contra as precariedades.

\section{Conclusão}

É possível concluir que muitas famílias no Guarituba vivem desigualmente a cotidianidade, com momentos de alienação e desalienação (comunitária), com a presença de um poder público que se manifesta por uma ausência, não reconhecendo o cotidiano como forma relevante de análise e atuação. Essa ausência, conforme se constatou, tem graves consequências, que interferem na implementação de projetos urbanos, apontando ser necessário e possível a inter-relação entre planejamento urbano e cotidianidade, ao invés do que ocorre, qual seja, uma mútua redução.

Dessa forma, a vida cotidiana e a cotidianidade constituem-se em dimensão, campo e escala válidos e, sobretudo, necessários para a atuação do planejamento urbano, devendo estar em sua base, enraizadas entre a teoria e a prática. Sendo assim, a investigação aponta que gestores públicos, acadêmicos e também a população não podem se abster do aprofundamento no estudo da vida cotidiana e da cotidianidade, como importante dimensão para o planejamento urbano. É emergencial repensar o significado da atuação interescalar, do plano à sua execução.

O planejamento urbano deve ter um papel mediador das contradições observadas, aprofundando-se em reflexões existentes, como o conceito de um planejamento subversivo (Randolph, 2014). Para o autor, o Estado tem atuado de forma a abstrair as manifestações insurgentes, encarando-as como temporárias. Seu conceito de planejamento subversivo trabalha justamente o aproveitamento das experiências insurgentes, mas atuando na base de sua formação, na dimensão da cotidianidade. É subversivo porque, ao não confrontar diretamente o sistema, cria "na práxis cotidiana formas duradouras que não se submetem às forças colonizadoras dos sistemas" e está "baseada na própria ignorância do sistema em reconhecer a integração social como elemento estrutural para a sua sobrevivência" (ibid., p. 48). 
Nesse sentido, vale refletir também sobre o pensamento de Souza (2002) que acredita em formas de desenvolvimento socioespacial por meio do princípio da autonomia de Cornelius Castoriadis. Para Souza, não se trata de eliminar a figura do Estado radicalmente, mas de compreender o processo envolvido nos diferentes graus de autonomia que existem ou podem existir, o que permitiria, ao Estado, vislumbrar e protagonizar soluções a partir do aumento do grau de autonomia dos desprivilegiados. Entende que conflito e poder não estarão nunca ausentes, pois uma sociedade dita justa deveria ser aquela que deixa constantemente aberta a possibilidade de discussão sobre as leis que adotou como justas.
Uma sociedade autônoma iria, dessa forma, sendo construída ao longo do tempo, a partir da abolição gradual da separação entre dirigentes e dirigidos "dando-se a oportunidade de surgimento de uma esfera pública dotada de vitalidade e animada por cidadãos conscientes, responsáveis e participantes" (ibid., p. 175). Mesmo que esteja implícita a ideia de gradualismo em Souza, o autor deixa claro que a necessidade da "participação popular" deve ser radicalizada ao máximo, não se devendo contentar com o modelo da participação por consensos.

São discussões que se integram à velha, mas nem por isso obsoleta, luta pelo direito à cidade, considerando, contudo, e, por fim, o planejamento com base na cotidianidade.

\section{[1] https://orcid.org/0000-0003-2440-7510}

Instituto de Pesquisa Econômica Aplicada, Diretoria de Estudos e Políticas Regionais Urbanas e Ambientais. Curitiba, PR/Brasil.

Observatório das Metrópoles, Núcleo Curitiba. Curitiba, PR/Brasil. liriaok@gmail.com

\section{Notas}

(1) Livro resultante de simpósio realizado pela Associação Nacional de Pós-Graduação e Pesquisa em Planejamento Urbano e Regional (Anpur), em julho de 2013, o que demonstra a atualidade das discussões.

(2) População estimada pela autora a partir de dados por setores censitários do Censo Demográfico de 2010 (IBGE, 2010) que o Guarituba engloba.

(3) A análise feita por Lefebvre abarca o período a partir do pós-segunda guerra mundial, quando iniciou a escrever a série, dividida em três tomos, do livro Critique of everyday life (2014). Tomo I - "Introdução" (1977); Tomo II - "Fundamentos de uma sociologia da cotidianidade" (1980); e o Tomo III - "Da modernidade ao modernismo, por uma metafilosofia do cotidiano" (1981). 
(4) Vila Lory, Jd. Assaí, Jd. Monte Líbano, Jd. Tocantins, Jd. Tarumã IV e Jd. Orquídeas.

(5) Que deixaram o Guarituba para formar a colônia Witmarsun em Palmeira/PR.

(6) Volochko (2011) chama a atenção, em sua tese, sobre o estabelecimento do que denomina cotidianidade desigual, que vai sendo produzida nos espaços ou entre as pessoas, cuja realidade vivida baseia-se em um infracotidiano, ligado à informalidade, podendo ser destacado, é ainda predominante no conjunto habitacional.

\section{Referências}

CARLOS, A. F. A. (2007). O lugar no(do) mundo. São Paulo, Labur Edições.

(2014). "A lógica do planejamento versus a dialética do mundo". In: LIMONAD, E; CASTRO, E. R. (orgs.). Um novo planejamento para um novo Brasil? Rio de Janeiro, Letra Capital.

COHAPAR - Companhia de Habitação do Paraná (2011). Projeto de trabalho técnico social. Curitiba, Cohapar.

COMEC - Coordenação da Região Metropolitana de Curitiba (1999). Área de Interesse Social do Guarituba. Curitiba, Comec.

DAMATTA, R. (1997). A casa \& a rua: espaço, cidadania, mulher e morte no Brasil. Rio de Janeiro, Rocco.

FERRAZ, M. (2016). Entrevista concedida pelo arquiteto coordenador da equipe que elaborou e executou as obras do Conjunto Habitacional Madre Teresa de Calcutá. Curitiba, 1ํnov.

HELLER, A. (2014). O cotidiano e a história. São Paulo, Paz e Terra.

HOLSTON, J. (2013). Cidadania insurgente: disjunções da democracia e da modernidade no Brasil. São Paulo, Companhia das Letras.

IBGE - Instituto Brasileiro de Geografia E Estatística (2010). Banco de Dados Agregados. Censo demográfico e contagem da população. IBGE. Disponível em: <http://www.sidra.ibge.gov.br/ bda/tabela/listabl.asp? c=3175\&z=cd\&o=7>. Acesso em: 29 ago 2016.

(2016). Banco de Dados Agregados. Censo demográfico e contagem da população. Disponível em: <http://www.sidra.ibge.gov.br/bda/tabela/listabl.asp? c=3175\&z=cd\&o=7>. Acesso em: 29 ago 2016.

JACOBS, J. (2000). Morte e vida de grandes cidades. São Paulo, Martins Fontes.

LEFEBVRE, H. (1968). A vida quotidiana no mundo moderno. Lisboa, Ulisseia Limitada.

(2014). Critique of everyday life (the one-volume edition). Nova York, Verso.

LIMONAD, E; CASTRO, E. (2014). Um novo planejamento para um novo Brasil? Rio de Janeiro, Letra Capital.

MAGNANI, J. G. C. (2002). De perto e de dentro: notas para uma etnografia urbana. Revista Brasileira de Ciências Sociais. São Paulo, v. 17, n. 49, pp. 11-29. 
MARCOS, V. de (2006). Trabalho de campo em geografia: reflexões sobre uma experiência de pesquisa participante. Boletim Paulista de Geografia, São Paulo, n. 84, pp. 105-136.

MARTINS, J. S. (1996). Henri Lefebvre e o retorno à dialética. São Paulo, Hucitec.

(2013). A sociabilidade do homem simples. São Paulo, Contexto.

(2014). Uma sociologia da vida cotidiana. São Paulo, Contexto.

PSOL - Partido Socialismo e Liberdade (2011). Toca de peixe - vídeo sobre ocupação em Guarituba. 27 fev. Disponível em: <https://www.youtube.com/watch?v=KIdzBLddpKg>. Acesso em: 3 set 2016.

RANDOLPH, R. (2014). "Subversão e planejamento como 'praxis'”. In: LIMONAD, E.; CASTRO, E. (orgs.). Um novo planejamento para um novo Brasil? Rio de Janeiro, Letra Capital.

SOUZA, M. L. (2002). Mudar a cidade: uma introdução crítica ao planejamento e à gestão urbanos. Rio de Janeiro, Bertrand Brasil.

VOLOCHKO, D. (2011). Novos espaços e cotidiano desigual nas periferias da metrópole. Tese de doutorado. São Paulo, Universidade de São Paulo.

Texto recebido em $4 / a b r / 2018$

Texto aprovado em 19/abr/2020 
